\title{
Correction to: Three-dimensional seismic sedimentology and stratigraphic architecture of prograding clinoforms, central Taranaki Basin, New Zealand
}

\author{
Maximilian Franzel $^{1,2} \cdot$ Stefan Back ${ }^{1}$ (1)
}

Published online: 3 January 2019

(c) Geologische Vereinigung e.V. (GV) 2019

\section{Correction to: International Journal of Earth Sciences https://doi.org/10.1007/s00531-018-1663-1}

In the online published article, Figs. 4 and 12 were published incorrectly. The correct Figs. 4 and 12 are given below.

The original article can be found online at https://doi.org/10.1007/ s00531-018-1663-1.

Stefan Back

stefan.back@emr.rwth-aachen.de

1 Geological Institute, Energy and Mineral Resources Group, RWTH Aachen University, Aachen, Germany

2 Department of Earth Sciences, Durham University, Durham, UK 


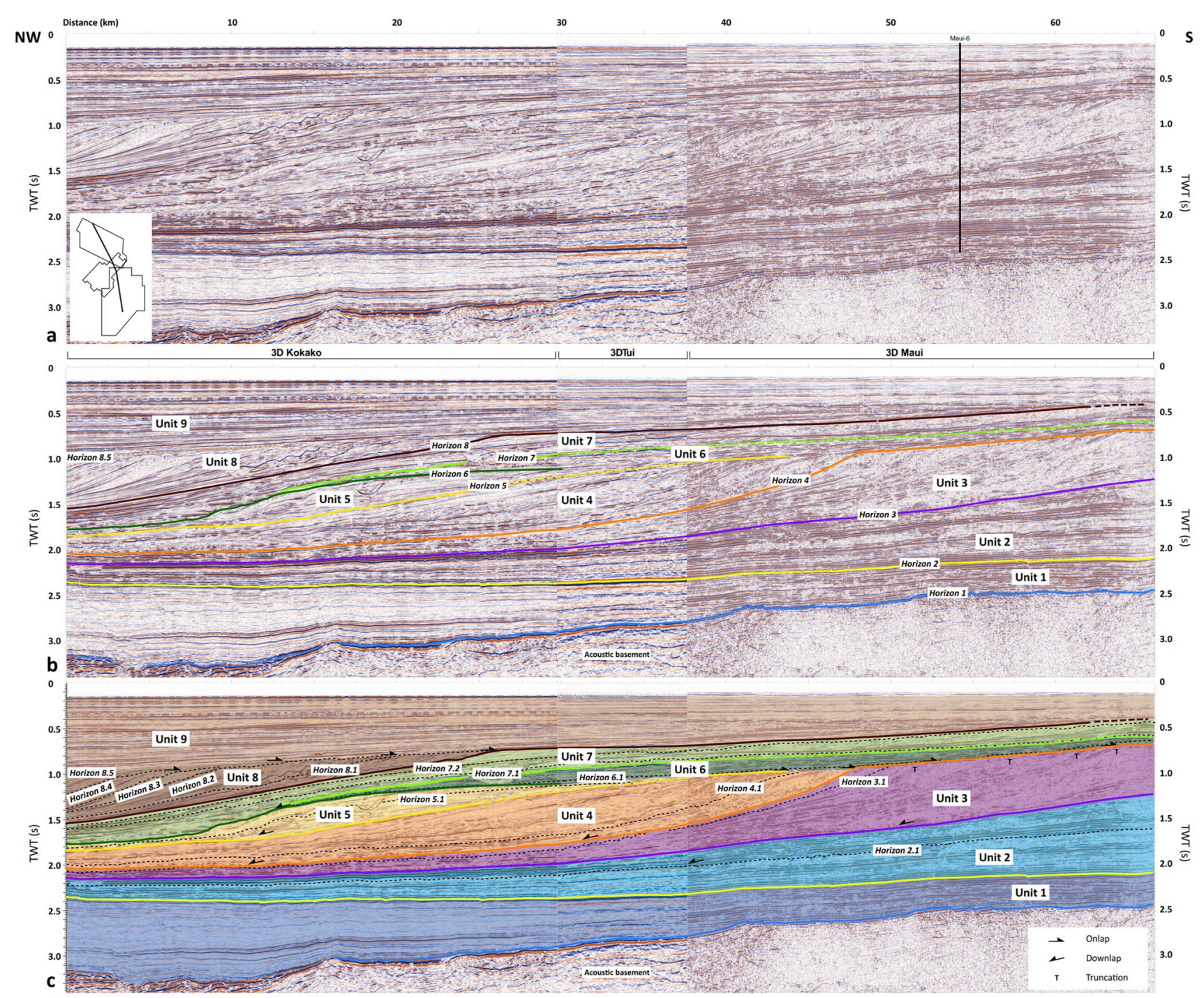

Fig. 4 Seismic overview section across the 3D Maui, 3D Tui, and 3D Kokako seismic-reflection volumes. For line location, see Fig. 2c and inset box. a Un-interpreted seismic section and location of borehole Maui-6. b Interpreted section with key marker horizons 1-8 (old to young) subdividing the studied clinoform succession into 9 seismic units (+acoustic basement). Dashed lines indicate areas in which downbuilding progradational, upbuilding progradational, and ret- rogradational units are separated by zones of reflection termination instead of a single sharp, precisely defined bounding reflection. c Interpreted section with seismic units 1-9 bound by key marker horizons (colour coding corresponds to Fig. 4). Also shown are intra-unit horizons (dashed black lines) that correspond to spectral-decomposition horizon slices and well data on Figs. 6, 7, 8, 9, 10, and 11 


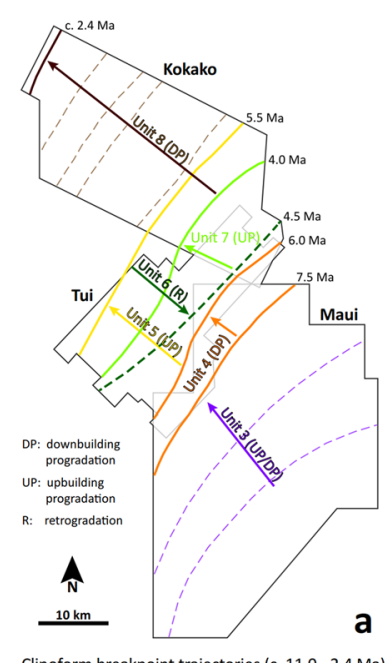

Clinoform breakpoint trajectories (c. 11.0 - 2.4 Ma)
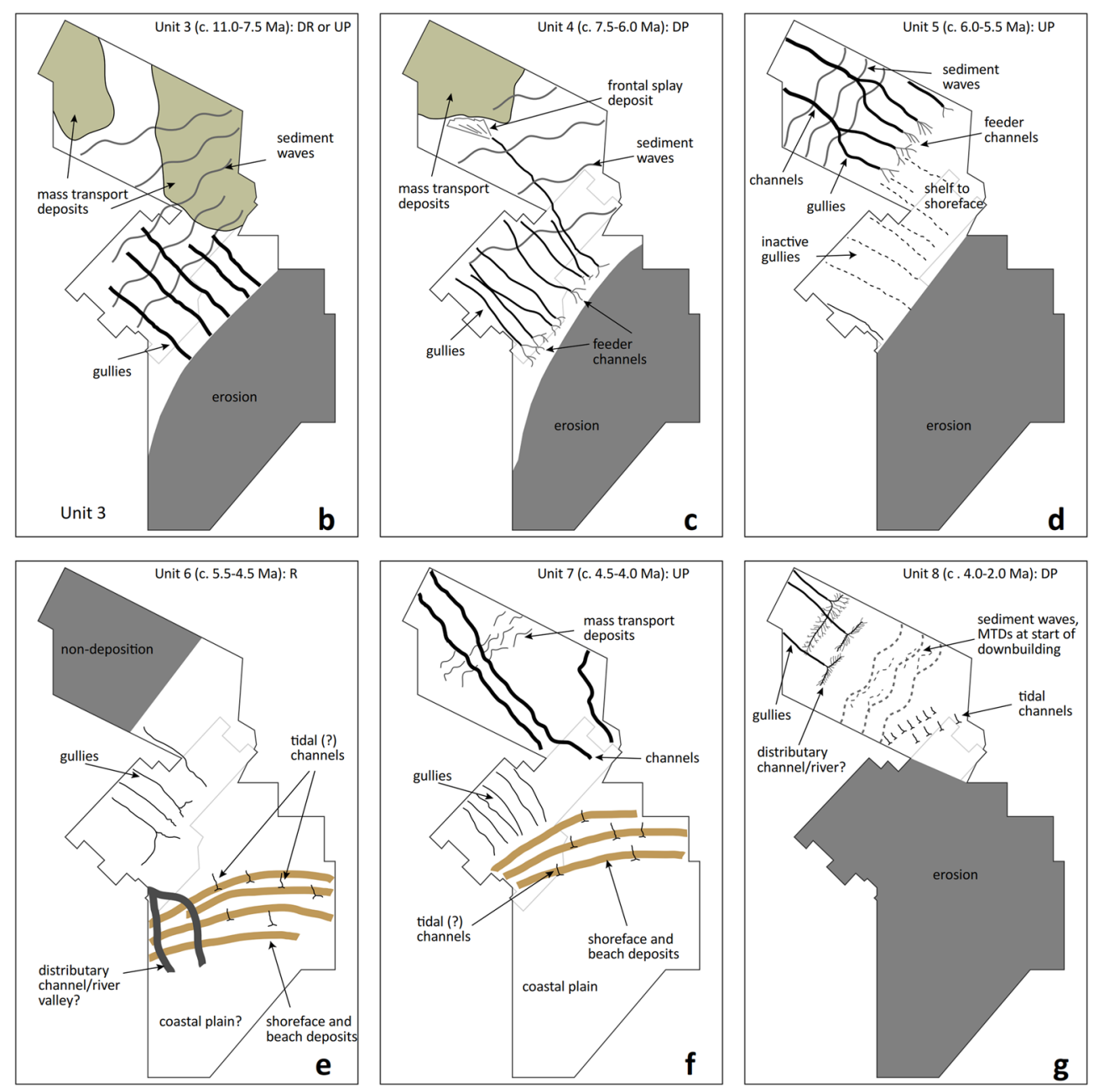

Fig. 12 Clinoform breakpoint migration and depositional elements of units 3 to 8 . a Clinoform breakpoint trajectories and approximate stratigraphic ages. Coloured lines indicate maximum progradation or retrogradation in each unit. Purple dashed lines in the Maui area show truncated clinoform foresets and brown dashed lines in the Kokako area indicate offlap breaks of individual clinoform packages. b-g Key depositional elements of each seismic unit. Note differences of depositional systems in units characterized by the same genetic architecture (downbuilding progradation, upbuilding progradation, and retrogradation) 